\title{
Mesenchymal stem/stromal cell-based therapies for COVID-19: First iteration of a living systematic review and meta-analysis MSCs and COVID-19
}

\author{
Aidan M. Kirkham ${ }^{1,6}$, Madeline Monaghan ${ }^{6}$, Adrian J.M. Bailey ${ }^{6}$, Risa Shorr $^{8}$, \\ Manoj M. Lalu ${ }^{2,3,6,7,9}$, Dean A. Fergusson ${ }^{4,5,6,10}$, David S. Allan ${ }^{1,4,6,7,10, *}$ \\ ${ }^{1}$ Departments of Biochemistry, Microbiology \& Immunology, University of Ottawa, Ottawa, ON, Canada \\ ${ }^{2}$ Cellular and Molecular Medicine, University of Ottawa, Ottawa, ON, Canada \\ ${ }^{3}$ Anesthesiology and Pain Medicine, University of Ottawa, Ottawa, ON, Canada \\ ${ }^{4}$ Medicine, University of Ottawa, Ottawa, ON, Canada \\ ${ }^{5}$ Epidemiology and Public Health, Faculty of Medicine, University of Ottawa, Ottawa, ON, Canada \\ ${ }^{6}$ Clinical Epidemiology, Ottawa Hospital Research Institute, Ottawa, ON, Canada \\ ${ }^{7}$ Regenerative Medicine, Ottawa Hospital Research Institute, Ottawa, ON, Canada \\ ${ }^{8}$ Medical Information and Learning Services, The Ottawa Hospital, Ottawa, ON, Canada \\ ${ }^{9}$ Departments Anesthesia, The Ottawa Hospital, Ottawa, ON, Canada \\ ${ }^{10}$ Medicine, The Ottawa Hospital, Ottawa, ON, Canada
}

\section{A R T I C L E I N F O}

\section{Article History:}

Received 7 September 2021

Accepted 9 December 2021

\section{Keywords:}

acute respiratory distress syndrome

coronavirus disease 2019

COVID-19

exosomes

extracellular vesicles

mesenchymal stem cells

mesenchymal stromal cells

microvesicles

pneumonia

SARS-CoV-2

sepsis

severe acute respiratory syndrome

coronavirus 2

\begin{abstract}
A B S T R A C T
Background: Mesenchymal stem/stromal cells (MSCs) and their secreted products are a promising therapy for COVID-19 given their immunomodulatory and tissue repair capabilities. Many small studies were launched at the onset of the pandemic, and repeated meta-analysis is critical to obtain timely and sufficient statistical power to determine efficacy.

Methods and Findings: All English-language published studies identified in our systematic search (up to February 3 , 2021) examining the use of MSC-derived products to treat patients with COVID-19 were identified. Risk of bias (RoB) was assessed for all studies. Nine studies were identified (189 patients), four of which were controlled (93 patients). Three of the controlled studies reported on mortality (primary analysis) and were pooled through random-effects meta-analysis. MSCs decreased the risk of death at study endpoint compared with controls (risk ratio, 0.18 ; $95 \%$ confidence interval $[\mathrm{Cl}], 0.04$ to $0.74 ; P=.02 ; I^{2}=0 \%$ ), although follow-up differed. Among secondary outcomes, interleukin-6 levels were most commonly reported and were decreased compared with controls (standardized mean difference, $-0.69 ; 95 \% \mathrm{CI},-1.15$ to $-0.22 ; P=.004 ; I^{2}=0 \%$ ) ( $\mathrm{n}=3$ studies). Other outcomes were not reported consistently, and pooled estimates of effect were not performed. Substantial heterogeneity was observed between studies in terms of study design. Adherence to published ISCT criteria for MSC characterization was low. In two of nine studies, RoB analysis revealed a low to moderate risk of bias in controlled studies, and uncontrolled case series were of good ( 3 studies) or fair (2 studies) quality.

Conclusion: Use of MSCs to treat COVID-19 appears promising; however, few studies were identified, and potential risk of bias was detected in all studies. More controlled studies that report uniform clinical outcomes and use MSC products that meet standard ISCT criteria should be performed. Future iterations of our systematic search should refine estimates of efficacy and clarify potential adverse effects.
\end{abstract}

(C) 2022 International Society for Cell \& Gene Therapy. Published by Elsevier Inc. All rights reserved.

\section{Introduction}

Severe acute respiratory syndrome coronavirus 2 (SARS-CoV-2), the pathogenic $\beta$-coronavirus that causes coronavirus disease 2019

\footnotetext{
* Corresponding Author: Dr. David Allan, Ottawa Hospital Research Institute, 501 Smyth Rd, Box 704 Ottawa ON K1H 8L6, Canada, Fax +1 613-737-8861.

E-mail address: daallan@toh.ca (D.S. Allan).
}

(COVID-19), has spread rapidly around the world, creating an urgent need for effective therapies that can prevent excessive mortality [1]. SARS-CoV-2 infects cells via attachment of its spike (S) protein to the angiotensin-converting enzyme 2 (ACE2) receptor on the surface of target cells [2]. The subsequent endocytosis of the ACE2 complex leads to increased free serum angiotensin II (Ang II), which can induce profound inflammatory responses through binding with 
angiotensin receptor type 1 and activation of the nuclear factor $-\kappa \mathrm{B}$ (NF- $\kappa \mathrm{B}$ ) pathway [3], as well as the conversion of membrane bound interleukin (IL)-6R $\alpha$ to soluble IL-6 (sIL-6), activating signal transducer and activator of transcription 3 (STAT3) [3]. The synergistic activation of NF- $\kappa$ B and STAT3 creates a positive feedback loop that further augments the production of pro-inflammatory cytokines and chemokines [3], attracting pro-inflammatory immune cells to infected tissues [4] and resulting in a dramatic augmentation in proinflammatory cytokine production termed the "cytokine storm" [5]. This cytokine storm causes considerable tissue damage through apoptosis, necroptosis [6] and pyroptosis [7]. Pro-inflammatory responses and the cytokine storm induced by SARS-CoV-2 infection can lead to pulmonary complications including acute lung injury, pulmonary edema and acute respiratory distress syndrome (ARDS) $[8,9]$, which may require intubation and ventilator support in intensive care units (ICUs).

Since SARS-CoV-2 first emerged in December 2019, few approved therapies have emerged to supplement the ongoing COVID-19 vaccination efforts that have been launched [10]. With many people remaining vulnerable because of slower uptake of vaccinations in some areas, combined with the emergence of increasing variants of concern, the need for effective therapy remains a pressing issue.

Mesenchymal stem/stromal cells (MSCs) were quickly viewed with significant promise to treat COVID-19 [11], and many studies were launched rapidly, with several now completed and reported. MSCs are multipotent stem-like cells that can be isolated from a number of adult and neonatal tissues including bone marrow, adipose tissue, umbilical cord and placenta [12]. MSCs have demonstrated immunomodulatory, antimicrobial and tissue-regenerative capabilities across a wide variety of diseases in both preclinical and clinical studies [13-17) (see Box 1 for a summary of mechanisms of immune modulation by MSCs). After migration to sites of infection or injury, MSCs can reduce neutrophil infiltration [18], suppress CD8 ${ }^{+} \mathrm{T}$ cell proliferation, polarize pro-inflammatory M1 macrophages and T helper 1 (Th1) $\mathrm{CD}^{+} \mathrm{T}$ cells to anti-inflammatory M2 macrophages and $\mathrm{Th} 2 \mathrm{CD} 4^{+} \mathrm{T}$ cells, promote regulatory $\mathrm{T}$ cell ( $\mathrm{T}$ reg) and regulatory $B$ cell (B reg) function, suppress dendritic cell maturation and function, and modulate natural killer (NK) cell activity [19]. The immunomodulatory actions of MSCs on these immune cells are mediated through the secretion of many soluble factors $[18,20]$ and through direct cell-cell contact, and MSCs may target the IL-6 amplifier protein directly by attenuating the hyperactivation of NF- $\kappa$ B and STAT3 $[21,22]$. The vast majority of preclinical and clinical studies examining the use of MSC-based therapeutics have found that MSCs have minimal immunogenicity when administered to patients $[23,24]$ and do not lead to further inflammation or worsening of the cytokine storm. Moreover, the occurrence of adverse events resulting from MSC therapy is rare $[25,26]$.

An emerging method of conducting systematic reviews are living systematic reviews, which involve frequent updating to incorporate new evidence as soon as it becomes available, providing clinicians, scientists and policymakers with the most up-to-date, high-quality information surrounding specific topics [27]. Living systematic reviews have been recently conducted to provide estimates regarding the safety and efficacy for many repurposed therapeutics in the context of COVID-19 [28-30) and seem most appropriate for the analysis of MSCs in COVID-19, with the expectation that many studies were launched early in the pandemic and will be published over the ensuing 12 to 18 months [31].

Pooled estimates regarding the use of MSCs to treat patients with COVID-19 are needed, as nearly all studies in this area are small and lack sufficient statistical power to determine efficacy on their own. Meta-analysis may be limited, however, by heterogeneity in aspects of study design, product characterization, outcome measures and differences in participant populations enrolled between studies. Timely regulatory approval and clinical translation will likely require meta- analysis of similar high-quality, well-designed studies identified through a systematic search of the literature to determine whether MSC-based therapeutics are safe and effective for the treatment of COVID-19. A living systematic review and meta-analysis is needed to keep pace with the rapid evolution of new information related to the pandemic and to provide insight from a combined sample size that will have sufficient power for determining efficacy.

\section{Methods}

This systematic review is reported in accordance with the Preferred Reporting Items for Systematic reviews and Meta-Analysis (PRISMA) guidelines [32] (Figure S1.). The study protocol has been published [33] and is registered at the International Prospective Registry of Systematic Reviews (PROSPERO; CRD42021225431).

\section{Literature search strategy}

A systematic search of all clinical studies (controlled and uncontrolled) examining the use of MSCs and/or their secretome (which includes conditioned media [MSC-CM] or extracellular vesicles [MSCEVs] derived from MSCs) as a therapeutic intervention was conducted from 1947 to February 3, 2021, in Embase Classic+Embase, Ovid MEDLINE, Ovid EBM Reviews and the Cochrane Central Register of Controlled Trials. The search strategy was developed in collaboration with a health sciences librarian (R. Shorr) specializing in systematic review searches and was peer-reviewed by a second librarian according to the Peer Review of Electronic Search Strategies (PRESS) framework [34]. The reference lists of included studies and relevant reviews captured by the search were also examined by two independent reviewers (A.M. Kirkham, M. Monaghan) to ensure that all relevant articles were captured. The full search strategy is outlined in Figure S2.

\section{Eligibility criteria}

All English-language, full-text, clinical studies examining the use of MSCs or their secretome (MSC-EVs, MSC-CM) as a therapeutic intervention for COVID-19 were included. Studies could be single armed (uncontrolled) or have a comparator or control groups (controlled). For the controlled studies, all randomization methods were considered acceptable (randomized, pseudo-randomized, and nonrandomized). Studies published in languages other than English, review articles, commentaries, editorials, letters, case reports, conference abstracts, unpublished gray literature and other study types (in vitro studies, preclinical animal studies, etc.) were excluded. All symptomatic or asymptomatic patients with confirmed SARS-CoV-2 infection (quantitative RT-PCR, antibody assay, etc.) were included. MSCs derived from any known applicable tissue source (bone marrow, adipose tissue, umbilical cord, dental pulp, placenta, etc.) were acceptable. MSCs could be obtained from syngeneic, allogeneic or xenogeneic tissues. All routes of MSC/secretome administration were acceptable (intravenous injection, aerosol inhalation, intramuscular injection, etc.). MSC-based products could also be administered along with other therapeutic agents (antivirals, anti-cytokine drugs, immunomodulatory agents, etc.). Studies exclusively investigating other non-MSC-based therapeutics were excluded.

\section{Outcomes}

The primary analysis of this study was mortality rate at study endpoint. Secondary analyses included number of patients requiring ICU admission; number of patients requiring mechanical ventilation; length of time in hospital, in ICU or on mechanical ventilation; presence and severity of clinical symptoms (fever, cough, shortness of breath, chest pain, etc.); presence and size of pulmonary lesions on radiographic imaging (i.e., computed tomography scan); change in 
oxygenation levels (e.g., $\mathrm{PaO}_{2} / \mathrm{FiO}_{2}$ ratio), viral load and body temperature; organ failure assessment score (e.g., Sequential Organ Failure Assessment [SOFA]); circulating levels of immune cells (lymphocytes, neutrophils, macrophages, regulatory dendritic cells, NK cells, etc.), pro-inflammatory cytokines (IL -6 , tumor necrosis factor [TNF]- $\alpha$, interferon [IFN] $-\gamma$, etc.), anti-inflammatory cytokines (IL-10, transforming growth factor [TGF]- $\beta$, etc.) and inflammatory markers ( $\mathrm{C}$-reactive protein, ferritin, D-dimer, etc.); and adverse events arising from MSC-based product administration (tumorigenesis, thromboembolism, etc.)

\section{Study selection}

All citations identified in the search were imported into Rayyan (https:// rayyan.qcri.org/) for management of search records. After duplicates were removed, the study titles and abstracts were screened in duplicate by two independent reviewers (A.M. Kirkham, M. Monaghan). After all potentially relevant titles and abstracts were identified, the full texts of all potentially relevant studies were reviewed in duplicate to determine final eligibility. In cases of disagreement between the two reviewers, consensus was achieved through discussion with a third senior team member (D.S. Allan).

\section{Data extraction}

All relevant data was extracted in duplicate by two independent reviewers (A.M. Kirkham, M. Monaghan) from the included studies using a standardized data extraction template in Microsoft Excel (Microsoft, Seattle, WA). In cases of disagreement between the two reviewers, the differences were resolved through consultation with a senior team member (D.S. Allan). Specific data extracted from studies included study characteristics (e.g., authors, publication year, country of study), study design (characteristics of control group, sample size, length of observation period, planned preconditioning or alterations to MSCs or secreted factors before therapeutic use, MSC/secretome isolation and characterization methods, etc.), patient characteristics (age, sex, comorbidities, COVID-19 severity, symptoms upon hospital admission, etc.), intervention characteristics (MSC tissue source, $\mathrm{MSC} /$ secretome dose, route of administration, number of doses, whether MSC-based products met all of the minimal criteria established in guidelines by the International Society for Cellular Therapy [ISCT] [35] and/or Minimal Information for Studies of Extracellular Vesicles [MISEV] [36] criteria), all data pertaining to primary and secondary outcomes, and details concerning risk of bias (RoB) determination. RoB assessment was conducted using the Risk-of-Bias Tool for Randomized Trials (ROB 2) [37] for randomized controlled trials, the Risk of Bias in Non-randomized Studies of Interventions (ROBINS I tool) [38] for non-randomized controlled studies, and the Evidence Based Medicine (EBM) tool [39] for case series. ImageJ software was used to extract data in graphical format (https://imagej.nih.gov/ij/ download.html).

\section{Data analysis}

The results from individual studies were pooled for meta-analysis using Review Manager (version 5.4) Systematic Review Software (https://training.cochrane.org/online-learning/core-software-

cochrane-reviews/revman/revman-5-download). For dichotomous outcomes, risk ratios (RRs) were calculated to determine the risk of death between the control and experimental groups at study endpoint. For continuous outcomes, the standardized mean difference (SMD) between control and experimental groups was calculated using random effects meta-analyses. Significance in pooled analysis was performed using the DerSimonian and Laird random effects model. All data is presented with 95\% confidence intervals (CIs). Meta-analysis was performed only when three or more controlled studies reported on the same outcome. Outcomes that were reported in fewer than three controlled studies or for which adequate data for inclusion in meta-analysis was not provided were analyzed in a descriptive manner. Statistical heterogeneity was assessed using the $I^{2}$ statistic. Potential subgroup analyses were determined a priori in our study protocol with the goal of determining if the effect of MSCs as a therapeutic intervention for COVID-19 was significantly different for studies that used MSCs from specific tissue sources, MSCs versus secreted factors (MSC-EVs, MSC-CM), or in patients with varying COVID-19 severity. Because of the small number of studies included in each of our quantitative analyses, we did not perform a planned analysis for publication bias. Finally, $P<.05$ was considered significant for all analyses.

\section{Results}

\section{Literature search}

A total of 459 unique records were identified in our systematic search of the literature after duplicates were removed. Nine articles met the criteria for inclusion in our analysis [40-48). Reasons for study exclusion were trial protocol only $(n=57)$; reviews, editorials or commentaries $(n=9)$; non-MSC cells $(n=8)$; and uncontrolled case series in languages other than English $(n=4$; one Spanish, one Chinese, one Persian, and one Russian) (Figure 1).

\section{Study characteristics}

The characteristics of the nine included studies are summarized in Table 1. Four of the studies were controlled [40-43), and five were uncontrolled [44-48). Two of the controlled studies were randomized controlled trials (RCTs) [41,43], and two were nonrandomized controlled trials $[40,42]$. All five of the uncontrolled studies were case series [44-48). Study publication date ranged from March 9, 2020, to January 29, 2021. Five of the studies were conducted in China $[40-42,45,46]$, two in the United States [43,44], one in Iran [48] and one in Spain [47].

\section{Patient characteristics}

In total, there were 189 patients (mean age $58.3 \pm 6.3$ years; 124 male) enrolled across all study groups, and 136 patients (mean age $58.5 \pm 6.7$ years; 96 male) were administered MSC-based therapy as a therapeutic intervention for COVID-19. In the controlled studies, 40 patients ( $55.5 \pm 7.1$ years of age; 24 male) were treated with MSCs, and 53 patients $(57.9 \pm 6.4$ years of age; 28 male) served as controls. The distribution of patients with mild, moderate, severe and critical COVID-19 at the time of treatment with MSC-based treatment was somewhat similar for patients in the intervention groups and controls; however, there were more patients with mild COVID-19 and fewer with severe disease in the intervention group compared with the control group (Table 1 ).

In terms of patient comorbidities, there were more obese patients in the intervention group compared with controls $(27.5 \%$ versus $9.4 \%)$. However, all other comorbidities, including hypertension, diabetes, chronic obstructive pulmonary disease (COPD), coronary artery disease and hyperlipidemia, appeared well balanced between control and intervention groups (Table 1 ).

\section{Intervention characteristics}

Intervention characteristics are summarized in Table 2. Eight studies used MSCs [40-43,45-48), and one study used MSC-EVs (exosomes) [44]. All MSCs were derived from allogeneic human tissues, including umbilical cord $(n=5)[41-43,45,46]$, bone marrow $(n=1)$ [44] and adipose tissue $(n=1)$ [47]. One study used MSCs derived from both umbilical cord and placental tissue [48]. One study did not 


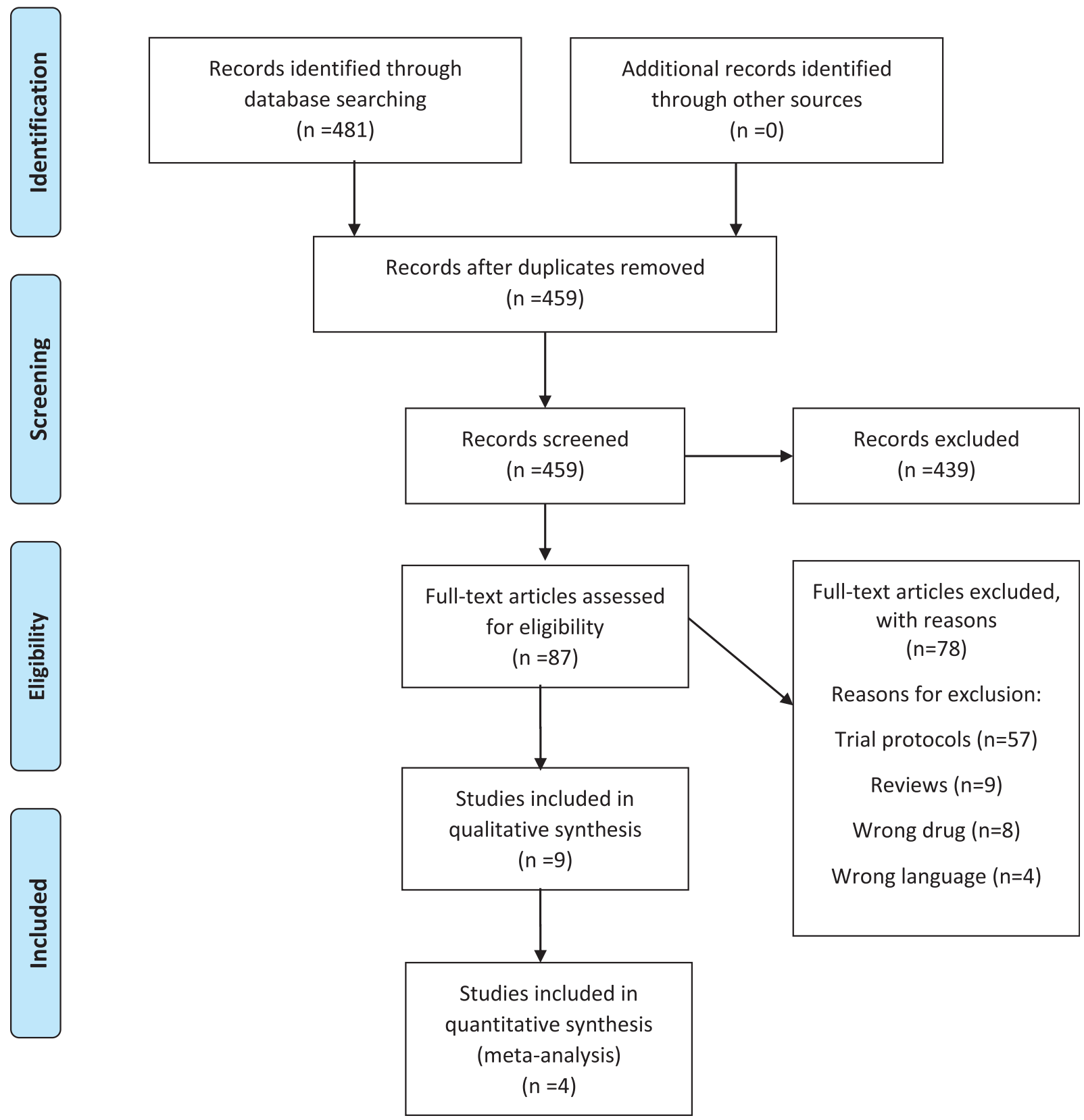

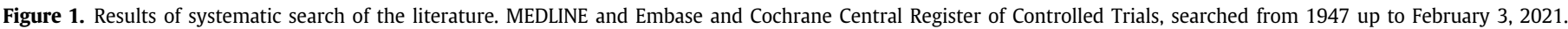
(Color version of figure is available online.)

report the tissue source for MSCs [40]. The passage number of the MSCs varied widely between studies (see Table 2], with four studies not reporting how many passages were performed before harvesting MSCs from ex vivo culture. With regard to the extent that studies reported on specific ISCT criteria [35] for MSC characterization, only two of the nine studies addressed all three minimal criteria established by the ISCT. Specific details regarding the number of studies meeting each of the three individual ISCT criteria can be found in Table 2. The study that used MSC-EVs (termed exosomes in the study) did not report sufficient details to allow classification of the EVs within the MISEV [36] criteria for characterization.

MSC doses varied and the format of reporting dose differed between studies, including cells per kilogram of body weight $(n=4$; 1 to $2 \times 10^{6}$ cells $/ \mathrm{kg}$ ), total cells per injection $\left(\mathrm{n}=4 ; 0.3\right.$ to $2.0 \times 10^{8}$ cells) and milliliters of ExoFlo $(\mathrm{n}=1 ; 15 \mathrm{~mL})$ in the case of MSC-EVs. All nine studies administered their product intravenously. Most patients (41.9\%) received one infusion of MSCs, although other studies reported administering up to four MSC infusions (see Table 2). The reported time from COVID-19 diagnosis to MSC administration (median of 6.5 days across studies, $\mathrm{n}=8$, range 1 to 15 ) was similar between control groups (4.0 days, range 1 to 14) and intervention groups (5.9 days, range 1 to 11.5 ) in the controlled studies.

Patients were administered other therapeutic agents in addition to MSCs or MSC-EVs in eight of the nine studies (88\%). The specific therapeutic agents administered varied considerably between studies and are summarized in Table 3. Two of the studies stated that they used medications in addition to MSCs but did not specify what medications were used. The median period of follow-up after MSC administration was 22.0 days (range 14 to 60 ).

\section{Primary outcome: mortality}

Outcomes reported across studies are summarized in Table 4. All nine studies reported mortality. The mortality rate at endpoint for all 
Table 1

Characteristics of patients enrolled in clinical studies of mesenchymal stromal cells (MSCs) as a therapeutic intervention for COVID-19.

\begin{tabular}{llll}
\hline Patient characteristics & $\begin{array}{l}\text { All studies } \\
(\mathrm{n}=9)\end{array}$ & \multicolumn{2}{c}{ Controlled studies (n=4) } \\
\cline { 2 - 4 } & & Control groups & MSC groups \\
\hline Number of patients & 189 & 53 & 40 \\
Male sex (\%) & 65.6 & 52.8 & 60.0 \\
Age (y) & $58.3(6.3)$ & $57.9(6.4)$ & $55.5(7.1)$ \\
Covid-19 severity & & & \\
Mild & $9(4.8)$ & $3(5.7)$ & $5(12.5)$ \\
Moderate & $30(15.9)$ & $5(9.4)$ & $5(12.5)$ \\
Severe & $123(65.1)$ & $45(84.9)$ & $29(72.5)$ \\
$\quad$ Critical & $27(14.3)$ & $0(0.0)$ & $1(2.5)$ \\
Comorbidities & & & \\
Hypertension & $71(37.6)$ & $16(30.2)$ & $13(32.5)$ \\
$\begin{array}{l}\text { Diabetes } \\
\text { Obesity }\end{array}$ & $56(29.6)$ & $11(20.8)$ & $9(22.5)$ \\
Chronic obstructive & $16(8.5)$ & $5(9.4)$ & $11(27.5)$ \\
pulmonary disease & $8(4.2)$ & $0(0.0)$ & $0(0.0)$ \\
Coronary artery & $9(4.7)$ & $3(5.7)$ & $1(2.5)$ \\
disease & & & \\
Hyperlipidemia & $5(2.6)$ & $0(0.0)$ & $0(0.0)$ \\
Chronic kidney failure & $3(1.6)$ & $0(0.0)$ & $0(0.0)$ \\
Other* & $20(10.6)$ & $3(5.7)$ & $0(0.0)$ \\
Follow-up (d) & $22(14$ to 60) & $21(14$ to 28) & $21(14$ to 28) \\
\hline
\end{tabular}

Data are $\mathrm{n}(\%)$ or mean (standard deviation) unless noted otherwise.

*Includes ex-smoker, pre-diabetes, asthma.

Table 2

Intervention characteristics for clinical studies of patients administered mesenchymal stromal cells (MSCs) as a therapeutic intervention for COVID-19.

\begin{tabular}{|c|c|c|}
\hline Intervention & Total Studies, $\mathrm{n}$ & $\begin{array}{l}\text { Controlled } \\
\text { studies, } \mathrm{n}\end{array}$ \\
\hline \multicolumn{3}{|l|}{ MSC product } \\
\hline MSCs & 8 & 4 \\
\hline MSC-EVs & 1 & 0 \\
\hline \multicolumn{3}{|l|}{ Donor type } \\
\hline Allogeneic & 9 & 4 \\
\hline Autologous & 0 & 0 \\
\hline \multicolumn{3}{|l|}{ MSC tissue source } \\
\hline Umbilical cord/placenta & 6 & 3 \\
\hline Adipose tissue & 1 & 0 \\
\hline Bone marrow & 1 & 0 \\
\hline Not described & 1 & 1 \\
\hline \multicolumn{3}{|l|}{ Product dose } \\
\hline MSCs/kg (no. of studies) & 1 to $2 \times 10^{6}(4)$ & 1 to $2 \times 10^{6}(2)$ \\
\hline Total MSCs (no. of studies) & 0.3 to $2.0 \times 10^{8}(4)$ & 0.3 to $1.0 \times 10^{8}(2)$ \\
\hline $\begin{array}{l}\text { mL of ExoFlo MSC-EVs (no. of } \\
\text { studies) }\end{array}$ & $15(1)$ & NA \\
\hline \multicolumn{3}{|l|}{ MSC infusions } \\
\hline 1 & $57(41.9)$ & $19(47.5)$ \\
\hline 2 & $31(22.2)$ & $12(30.0)$ \\
\hline 3 & $32(23.5)$ & $9(22.5)$ \\
\hline 4 & $16(11.8)$ & $0(0.0)$ \\
\hline \multicolumn{3}{|l|}{ ISCT criteria } \\
\hline $\begin{array}{l}\text { Met all three criteria (A, B, and } \\
\text { C below) }\end{array}$ & 2 & 1 \\
\hline (A) Plastic adherence & 2 & 1 \\
\hline (B) Trilineage differentiation & 3 & 2 \\
\hline $\begin{array}{l}\text { (C) Positive/negative surface } \\
\text { markers }\end{array}$ & 5 & 3 \\
\hline
\end{tabular}

Data are $\mathrm{n}$ or $\mathrm{n}(\%)$ unless noted otherwise. EV, extracellular vesicle; ISCT, International Society of Cellular Therapy; NA, not applicable.

patients administered MSCs or MSC-EVs was 17 of 136 patients (12.5\%). In the controlled studies, the mortality rate at endpoint for the combined control groups was 11 of 53 patients (20.7\%), whereas the mortality rate for the combined MSC groups was 1 of 40 patients (2.5\%). In meta-analysis of the controlled studies ( $\mathrm{n}=3$ ), MSCs were associated with a decreased risk of death at study endpoint (RR, 0.18; $95 \% \mathrm{CI}, 0.04$ to $0.74 ; P=.02, I^{2}=0 \%$ ) compared with the control group (Figure 2).

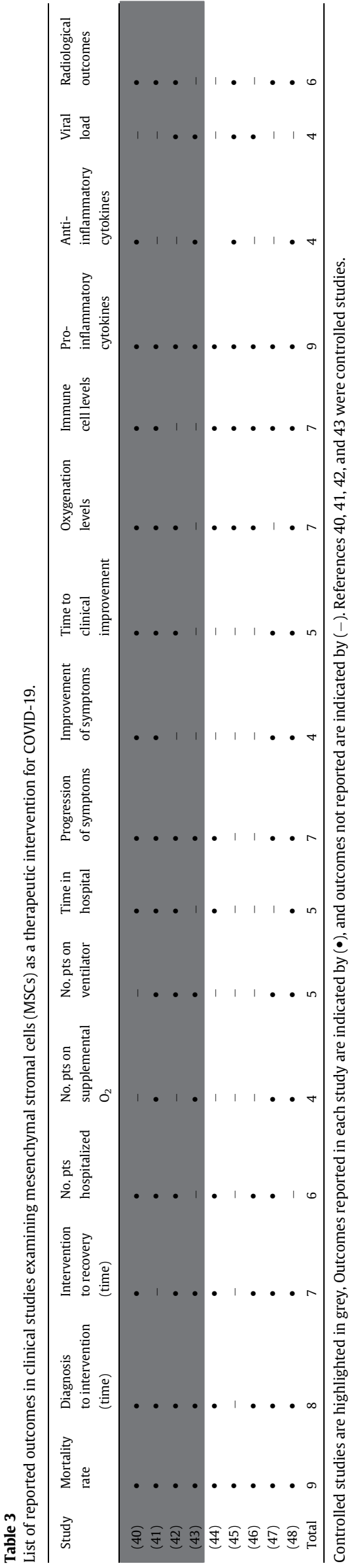


Table 4

Adverse events (AEs) and severe adverse events (SAEs) reported in clinical studies examining mesenchymal stromal cells (MSCs) as a therapeutic intervention for COVID-19. Controlled studies are highlighted in grey.

\begin{tabular}{llllll}
\hline Study & Safety lab values & Treatment-related AEs & Non-treatment-related AEs & Treatment-related SAEs & Non-treatment-related SAEs \\
\hline$(40)$ & - & - & - & - & - \\
$(41)$ & - & - & - & - & - \\
$(42)$ & - & - & - & - & - \\
$(43)$ & - & - & - & - & $\bullet$ \\
$(44)$ & - & - & - & - & - \\
$(45)$ & - & - & - & - & - \\
$(46)$ & - & - & - & - & - \\
$(47)$ & - & - & - & 0 & 4 \\
$(48)$ & - & - & 1 & \\
Total & 3 & 3 & & \\
\hline
\end{tabular}

AEs and SAEs reported in each study are indicated by $(\bullet)$, and AEs and SAEs not reported are indicated by $(-)$. References 40 , 41,42 , and 43 were controlled studies.

Secondary outcomes

Time to clinical improvement

Five studies (three controlled) reported on the median time from MSC administration to improvement of COVID-19 clinical symptoms (6.3 days, range 1.7 to 20.0, for all patients who received MSCs). In the three controlled studies, time from MSC administration to improvement of COVID-19 clinical symptoms was 23.0 days in control groups (range not defined, as patients did not improve in control groups of two studies) and 10.9 days (range 1.7 to 20.0) in MSC groups.

\section{Hospitalization and ICU metrics}

Six of the nine studies (three controlled) reported on the number of patients hospitalized for COVID-19 at the beginning and end of their study periods. All of the 97 patients (100\%) who received MSCs or MSC-EVs were hospitalized at time of enrollment, and only 32 of 97 patients (33.0\%) were still in hospital at the end of the respective study periods. In controlled studies, patients who received MSCs were less likely to remain hospitalized at the end of the study period compared with controls (odds ratio [OR], 0.34 ; $95 \% \mathrm{CI}, 0.12$ to 0.91 ; $P=.03])$.

Immune biomarkers

All nine studies reported pro-inflammatory cytokines at baseline and study endpoint. Three of the controlled studies reported serum IL-6 levels at study endpoint in a format that could be combined in meta-analysis, which revealed that MSCs significantly decreased serum IL-6 levels compared with controls (SMD, $-0.69 ; 95 \% \mathrm{CI}-1.15$ to $-0.22 ; P=.004 ; I^{2}=0 \%$ ) (Figure 3 ). Trends in several other proinflammatory cytokines from baseline to study endpoint were also observed among patients administered MSCs; however, none were consistently reported in enough of the controlled studies to perform meta-analysis. C-reactive protein changes were reported in seven studies (two controlled), and levels decreased in patients administered MSCs in all studies, with greater reductions in treated patients compared with controls. D-dimer levels decreased in three studies and increased in one study in patients administered MSCs. IFN- $\gamma$ declined from baseline to endpoint in patients given MSCs in all four

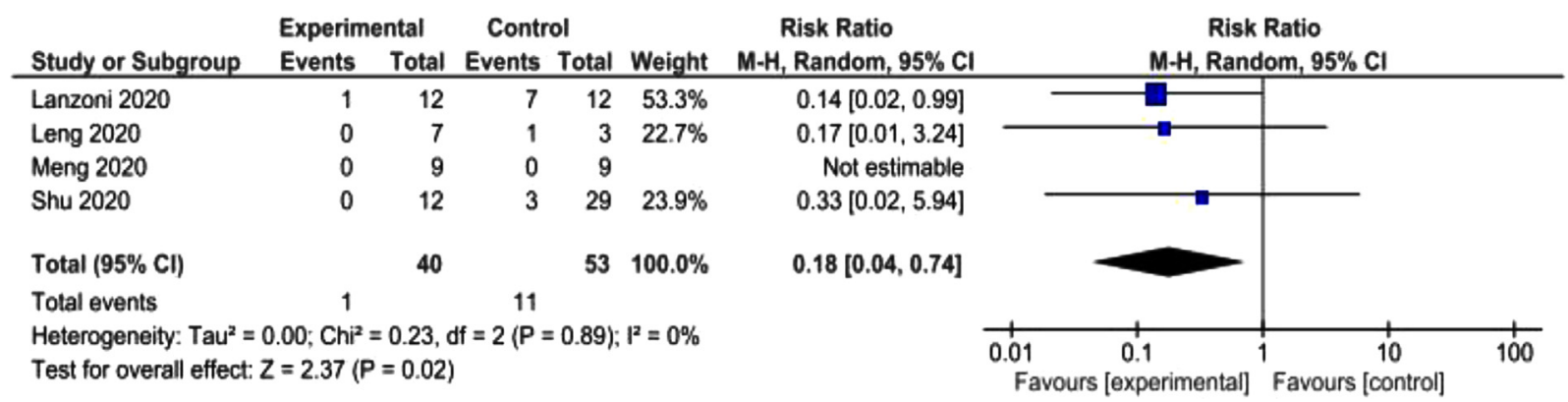

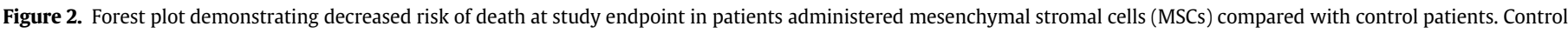
groups received standard of care for COVID-19 at the time of hospital admission, which varied depending on the institution. (Color version of figure is available online.)

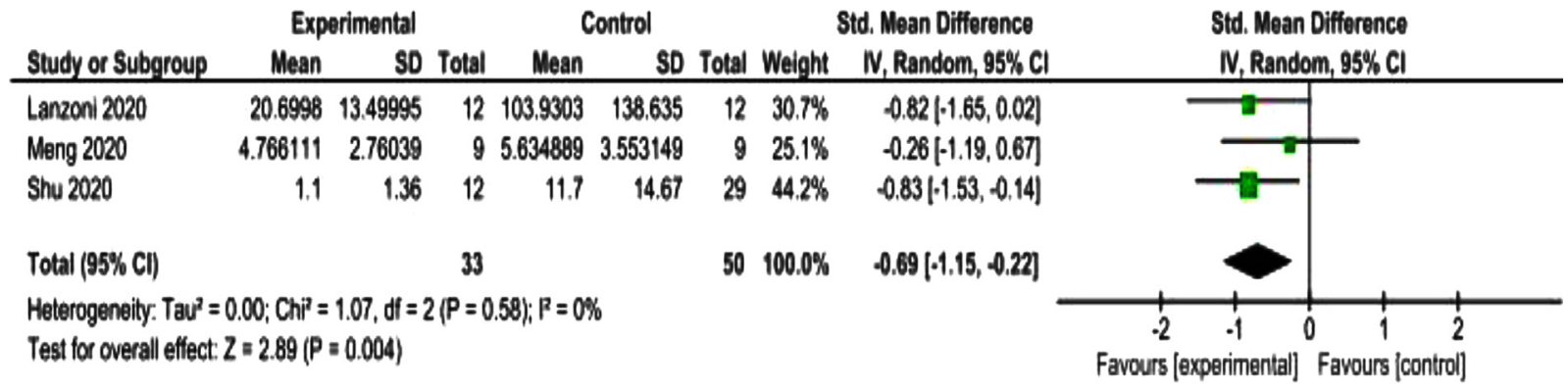

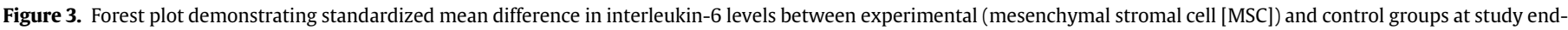
point. (Color version of figure is available online.) 
studies in which it was reported. TNF- $\alpha$ decreased from baseline to endpoint in patients administered MSCs in five studies.

Seven of the nine studies (two controlled) reported on changes in circulating levels of immune cells and/or other immune biomarkers. Lymphocyte count changes increased from baseline to endpoint in all seven studies (two controlled) that reported this outcome for patients who were administered MSCs.

\section{Radiological outcomes}

Six of the nine studies (three controlled) examined radiological improvement in patients after MSC administration. Five studies did so in a descriptive manner, with these studies reporting the disappearance of ground glass opacities, linear opacities and pleural effusions. One controlled study reported changes at 2 weeks in comparison to baseline and reported nonsignificant resolution of ground glass opacities (OR, $0.26 ; 95 \% \mathrm{CI}, 0.06$ to $1.09 ; P=.07$ ), linear opacities $(0.27 ; 0.07$ to $1.11 ; P=.07)$ and pleural effusions $(1.23 ; 0.10$ to $14.96 ; P=.87)$.

\section{Virological outcomes}

Four studies (two controlled) reported changes in viral load from baseline to study endpoint. At the beginning of these studies, all the patients administered MSCs (100\%) were positive for SARS-CoV-2 viral RNA. At the respective endpoints of these studies, none of the patients administered MSCs (0\%) were positive for SARS-CoV-2 viral RNA. Two studies (one controlled) reported on changes in SARS-CoV2 antibody titers in patients administered MSCs. Both studies displayed increasing antibody titers from baseline to endpoint in patients treated with MSCs compared with controls.

\section{Adverse events}

Adverse events are summarized in Table 5. Three studies reported adverse events associated with MSC infusion. These adverse events included facial flushing, transient fever and shivering. However, these symptoms resolved in all patients spontaneously or with minimal supportive treatment 1 to $24 \mathrm{~h}$ after MSC administration. Six studies reported no adverse events associated with MSC infusion. None of the studies reported severe adverse events associated with MSC infusion.

\section{RoB, publication bias and study quality}

RoB was assessed for the outcomes of mortality and IL-6 levels in RCTs. Regarding mortality, one RCT [43] was found to have low risk of bias, and the other RCT [41] had a risk of bias of "some concern$s "($ Table S1): the method of randomization was unclear, and it was unclear whether there were deviations from intended interventions or selection of reported results. Regarding changes in IL-6 levels, one
RCT [43] had a low risk of bias, and the other RCT [41] had some concerns regarding potential risk of bias (Table S2) as the method of randomization was unclear and it was unclear whether there were deviations from intended interventions, missing outcome data or selective reporting of results. For nonrandomized studies [40,42], both were found to have a moderate risk of bias (Table S3). Both studies had potential bias from confounding, measurement of outcomes (as studies did not mention blinding) and selection of reported results (as neither study preregistered their protocol). Of the included case series, three were found to be of good quality $[45,47,48]$ and two of fair quality $[44,46]$ (Table S4). Two of the case series did not present characterization of their MSCs $[44,46]$.

\section{Discussion}

Our systematic review and meta-analysis of clinical studies examining the use of MSCs and/or their secretome as a therapeutic intervention for COVID-19 demonstrated a positive therapeutic effect with minimal safety concerns, although the number of studies was limited. Meta-analysis revealed that MSCs decreased the risk of death, and we noted a decrease in IL-6 levels at study endpoint compared with control groups. Although we could not perform metaanalysis of other secondary outcomes owing to inconsistent reporting, MSCs also appeared promising with regard to decreasing proinflammatory cytokines and immune cells, increasing anti-inflammatory cytokines and immune cells, improving respiratory function and the oxygenation index, correcting abnormal radiological findings, ameliorating clinical symptoms, and reducing time in hospital, time in ICU, and time on mechanical ventilation. The strength of our conclusions, however, is limited by the small sample size and by the limited number of studies in this first edition of our living systematic review. We also detected potential reporting bias in all studies examined in our review. Reporting of common outcomes at uniform time points across studies, and use of MSC-based products characterized according to published minimal criteria from the ISCT [35] and MISEV [36], are key issues that must be addressed to overcome some of these observed differences between studies and will likely be necessary to accelerate translation of MSC-based therapeutics to mainstream clinical use. This could be facilitated through the use of a master protocol. Our primary analysis was mortality, given its clear relevance to lessening the paralytic and global impact of the pandemic. In a recently reported systematic review examining the efficacy of MSCs for ARDS, overall mortality appeared reduced, although not statistically different in the MSC group compared with the control group (RR, $0.63 ; 95 \% \mathrm{CI}, 0.21$ to $1.93 ; P=.064 ; I^{2}=35.8 \%$ ) [49]. Although some of the patients in this review had COVID-19-induced ARDS, other patients had a broad range of underlying causes for

Table 5

Concomitant therapies reported in studies. Controlled studies are highlighted in grey.

\begin{tabular}{|c|c|c|c|c|}
\hline Study (ref) & Antiviral agents & Antibiotic agents & Glucocorticoids & Transfusion-based interventions \\
\hline$(40)$ & None & None & None & None \\
\hline (41) & Abidor/oseltamivir & Moxifloxacin & Systemic glucocorticoids & None \\
\hline$(42)$ & Lopinavir/Ritonavir & None & Glucocorticoids & None \\
\hline (4) & "Best standard of care" & "Best standard of care" & "Best standard of care" & "Best standard of care" \\
\hline$(44)$ & None & Hydroxychloroquine, azithromycin & None & None \\
\hline (45) & "Concomitant medication" & "Concomitant medication" & "Concomitant medication" & "Concomitant medication" \\
\hline$(46)$ & $\begin{array}{l}\text { Umifenovir, interferon alfa-2b, } \\
\text { oseltamivir }\end{array}$ & Chloroquine & Methylprednisolone & $\begin{array}{l}\text { Intravenous immunoglobulin, intra- } \\
\text { venous albumin }\end{array}$ \\
\hline$(47)$ & $\begin{array}{l}\text { "Supportive therapy at discretion of } \\
\text { clinician" }\end{array}$ & $\begin{array}{l}\text { "Supportive therapy at discretion of } \\
\text { clinician" }\end{array}$ & $\begin{array}{l}\text { "Supportive therapy at discretion of } \\
\text { clinician" }\end{array}$ & $\begin{array}{l}\text { "Supportive therapy at discretion of } \\
\text { clinician" }\end{array}$ \\
\hline$(48)$ & $\begin{array}{l}\text { Lopinavir/ritonavir, ribavirin, favipir- } \\
\text { avir, Oseltamivir }\end{array}$ & $\begin{array}{l}\text { Hydroxychloroquine, azithromycin, } \\
\text { meropenem, vancomycin, imipe- } \\
\text { nem, colistin }\end{array}$ & None & Intravenous immunoglobulin \\
\hline
\end{tabular}

References 40, 41, 42, and 43 were controlled studies. 
ARDS (e.g., pneumonia due to H7N9). The most promising study in terms of mortality reduction in this previous analysis was the single COVID-19 study that was also included in our review. Given the favorable reduction in mortality observed in our meta-analysis, it is possible that MSCs are particularly well suited to treat ARDS caused by COVID-19. Although we were unable to perform subgroup analysis to examine the difference in mortality reduction between mild/moderate COVID-19 patients (not experiencing ARDS) and severe/critical COVID-19 patients (experiencing ARDS) in this edition of our living systematic review, we plan on performing a detailed analysis of this nature in future iterations.

IL-6 levels have received significant attention as a mediator of damaging inflammation in COVID-19, particularly as part of the cytokine storm in the pathogenesis of severe and critical cases [50]. Antagonists of IL-6 receptors such as tocilizumab have been investigated as treatment but have not yielded mortality benefits in studies reported so far [51-53). Moreover, IL-6 has been associated with prognostic significance for COVID-19 [54]. Our analysis identified that MSCs lowered IL-6 levels. Whether lowering IL-6 levels contributed directly to the observed mortality benefits remains unclear. Other mediators of inflammation were also variably reported and were lowered by MSC treatment in several studies in our review, including TNF- $\alpha$, IFN- $\gamma$ and IL-12. Additionally, a number of studies reported that MSC administration supported the production of antiinflammatory cytokines such as IL-10, TGF- $\beta$ and PGE2. Production of these anti-inflammatory cytokines by MSCs may further antagonize the pathogenic effects of pro-inflammatory cytokines [55]. Furthermore, MSCs and their secreted factors may also support the regeneration of tissues damaged by the cytokine storm through release of growth factors including hepatocyte growth factor, keratinocyte growth factor and vascular endothelial growth factor [56,57]. Thus, the pleiotropic anti-inflammatory and regenerative effects of MSCs may point to several potential mechanisms by which MSCs exert their apparent beneficial effect.

Although MSCs likely ameliorate COVID-19 through immunomodulation, MSCs may have modest constitutive immune-modulating properties [58-60). MSCs primed through exposure to pro-inflammatory mediators such as IFN- $\gamma$, TNF- $\alpha$ and IL- $1 \beta$ have more potent immune-modulating activity and secrete higher levels of soluble anti-inflammatory factors such as IDO and PGE2 [19]. In patients with severe or critical COVID-19, high levels of pro-inflammatory cytokines at the time of MSC treatment may induce a greater immune-modulatory phenotype, even without prior ex vivo priming [4,61], and in patients with mild or moderate COVID-19, induction of an immune modulatory phenotype in MSCs may be less complete [61]. The role of ex vivo priming of MSCs in the treatment of COVID19 was not identified in studies included in the first iteration of our systematic review and may be worth pursuing in future trials.

Only one study in our review examined the use of the MSC exosomes, which are part of the secretome, rather than MSCs themselves [44]. Exosomes, also referred to as small extracellular vesicles, are secreted from MSCs, range from 30 to $150 \mathrm{~nm}$ in size and are formed in multivesicular bodies within MSCs [62]. Studies have demonstrated that the therapeutic mechanisms of MSCs are largely mediated through the release of paracrine factors such as MSC-EVs [63]. MSC-EVs may also be amenable to a broader range of delivery methods, such as aerosol inhalation, which may be particularly relevant in the context of COVID-19 [64]. Although we were unable to perform subgroup analysis to compare the efficacy of MSC-EVs to their parent MSCs in this first edition of our living systematic review, we anticipate that an analysis of this nature will be possible in future updates.

All the studies in our review used third-party allogeneic MSCs. One of the reasons that allogeneic MSC therapy is favored over autologous MSC therapy is that third-party allogeneic MSCs can be used in an off-the-shelf manner when needed [65]. In contrast, autologous MSC therapy may introduce marked delays in treatment given the time and resources required to manufacture small batches of personalized autologous MSC products [66,67]. Furthermore, autologous MSCs from patients with advanced age or underlying health conditions have diminished therapeutic efficacy compared with allogeneic MSCs isolated from healthy donors [68,69,70].

The importance of tissue source for expanding MSCs has been addressed in previous reports of MSC treatment [71]. Most studies comparing the immunomodulatory properties of MSCs from different tissue sources have been performed in vitro. One study demonstrated that MSCs derived from adipose tissue (AT-MSCs) displayed superior inhibitory effects toward Th1 CD4 ${ }^{+} \mathrm{T}$ cells, $\mathrm{CD}^{+} \mathrm{T}$ cells and NK cells compared with UC-MSCs and BM-MSCs [72]. Moreover, UC-MSCs showed no inhibitory effects on B cells. Another study demonstrated that AT-MSCs have more potent immunomodulatory properties and exhibit greater IDO production compared with BM-MSCs [73]. For the treatment of COVID19, it may be important to select tissue sources that yield MSCs with reduced expression of or lack the ACE2 receptor [74,75]. This could allow MSCs to persist longer after administration in patients with COVID-19. In our review, there were an insufficient number of studies identified to perform subgroup analysis based on MSC tissue source. As more studies reach completion, future subgroup analyses of this nature may be possible.

Our study has limitations worthy of mention. The number of studies and patients included in this first iteration of our review remains small. This modest number of studies and patients limits the confidence in the observed effects. Although this initial number of published studies identified in our search is relatively small, many registered clinical trials dealing with the use of MSC-based products as a therapeutic intervention for COVID-19 were identified in a scoping review performed by our group [31]. Additionally, only two studies reported sufficient information that allowed us to confirm that MSC products met the minimal ISCT [35] or MISEV [36] criteria for characterization. Use of MSCs that vary in terms of product characterization may influence the observed effects and limit the ability to pool results from multiple studies. Significant heterogeneity was observed between studies in terms of outcome reporting. Mortality and levels of pro-inflammatory markers were the only outcomes reported by all nine studies included in our review. Inconsistent outcome reporting reduces the number of outcomes that can be combined in meta-analysis and limits interpretation of results. None of the studies in our review examined the use of MSCs along with other COVID-19 therapeutics. Administering MSCs along with other COVID-19 therapeutics may augment their beneficial effects. Potential reporting bias was also observed in all studies included in our review. Indeed, a framework for inclusion of studies that meet robust quality criteria could facilitate earlier regulatory review of MSC-derived products based on data from meta-analysis. Regulatory review for emergency use of new treatments retains more flexibility for approvals in many jurisdictions, and this mechanism of approval could be appropriate for MSCs given the challenges of conducting large studies. A framework for inclusion of high-quality studies is provided that could accelerate future regulatory reviews (see Table 6).

Our systematic review and meta-analysis suggest that MSCs are a promising treatment for COVID-19, although the certainty of this effect is limited by the small number of studies and modest numbers of patients enrolled, as well as substantial heterogeneity between studies in terms of study design, characterization of MSC products and outcome reporting. Future studies should consider our proposed framework for the inclusion of high-quality studies in future iterations of this meta-analysis to improve the consistency of outcome reporting and reduce heterogeneity, to refine our estimates of potential benefits and safety of MSCs to treat COVID-19. Demonstrating the benefit of MSCs to treat COVID-19 using our proposed framework for identifying the highest-quality evidence should accelerate regulatory approval of MSC-based therapies. With continued reporting of 
Box 1

Cellular mechanisms implicated in mesenchymal stromal cell (MSC)-based immune modulation.

\begin{tabular}{|c|c|c|}
\hline Cell process or target & Description & Reference \\
\hline Migration & $\begin{array}{l}\text { MSCs migrate in response to inflammatory mediators (cytokines and chemokines) and chemotactic gradients } \\
\text { (growth factors) produced by infection and/or tissue damage. MSC effects are mediated by release of soluble } \\
\text { factors or via direct cell-cell contact. }\end{array}$ & [18] \\
\hline Macrophage repolarization & $\begin{array}{l}\text { MSCs induce polarization of M1 macrophages (pro-inflammatory) to M2 macrophages (anti-inflammatory) } \\
\text { through secretion of IDO and PGE2. }\end{array}$ & [19] \\
\hline Dendritic cell (DC) inhibition & $\begin{array}{l}\text { MSCs reduce pro-inflammatory cytokine release, decrease antigen presentation capabilities and suppress differ- } \\
\text { entiation and maturation of DCs through secretion of PGE2 and IL-10. }\end{array}$ & [19] \\
\hline Natural killer (NK) cell regulation & $\begin{array}{l}\text { MSCs inhibit IFN- } \gamma \text { secretion and cytotoxic capabilities of NK cells through secretion of TGF- } \beta \text {, PGE2, IDO, IL-10 } \\
\text { and HGF. MSCs may promote the development of CD73 }{ }^{+} \text {regulatory NK cells. }\end{array}$ & [19] \\
\hline Neutrophil recruitment & $\begin{array}{l}\text { MSCs suppress NO secretion, inhibit respiratory bursts and decrease recruitment and infiltration of neutrophils } \\
\text { through secretion of IL-2, IL-4, IL-10, CXCL2 and CXCR2. }\end{array}$ & [18] \\
\hline B cell proliferation and regulation & $\begin{array}{l}\text { MSCs inhibit B cell proliferation by blocking the G0 and G1 phases of the cell cycle. MSCs also increase frequency } \\
\text { and activity of regulatory B cells through secretion of IL-10, TGF- } \beta \text { and IDO. }\end{array}$ & [19] \\
\hline $\mathrm{T}$ cell regulation & $\begin{array}{l}\text { MSCs induce polarization of Th1 } \mathrm{CD}^{+} \mathrm{T} \text { cells (pro-inflammatory) to Th2 (anti-inflammatory). MSCs may also } \\
\text { reduce activation, proliferation and differentiation of } \mathrm{CD} 4^{+} \text {pro-inflammatory Th1, Th17 and } \mathrm{CD} 8^{+} \mathrm{T} \text { cells } \\
\text { through secretion of TGF- } \beta 1 \text { and HGF. MSCs also reduce infiltration of } \mathrm{CD}^{+} \mathrm{T} \text { cells into the injured tissues by } \\
\text { up-regulating Foxp } 3^{+} \text {regulatory T cells. MSCs may also induce T cell apoptosis. }\end{array}$ & {$[18,19]$} \\
\hline Cell signaling & $\begin{array}{l}\text { MSCs may down-regulate the STAT3 signaling pathway through secretion of IL-17A. MSCs may suppress NF- } \kappa \text { B } \\
\text { activation through secretion of NRF and IGFBP-3. }\end{array}$ & {$[21,22]$} \\
\hline
\end{tabular}

CXCL2, C-X-C chemokine ligand 2; CXCR2, C-X-C receptor 2; HGF, hepatocyte growth factor; IDO, indolamine 2,3-dioxygenase; IFN- $\gamma$, interferon- $\gamma$; ; IGFBP-3, insulinlike growth factor binding protein 3IL, interleukin; NF- $\kappa$ B, nuclear factor- $\kappa \mathrm{B}$; NO, nitric oxide; NRF, nuclear receptor factor; PGE2, prostaglandin E2; STAT3, signal transducer and activator of transcription 3; TGF- $\beta$, transforming growth factor $\beta$; Th, Thelper type.

Table 6

Recommended criteria for performing meta-analysis for purposes of potential regulatory approval of mesenchymal stromal cell (MSC)-based therapy for COVID-19.

\begin{tabular}{|c|c|}
\hline Number of studies & $\begin{array}{l}\text { Sufficient number and similar enough to perform } \\
\text { meta-analysis that achieves the required power for } \\
\text { determining efficacy (see sample size). }\end{array}$ \\
\hline Study characteristics & $\begin{array}{l}\text { Controlled with contemporary and similar control } \\
\text { groups. Randomized is preferable. Concomitant } \\
\text { therapies should be controlled. }\end{array}$ \\
\hline Sample size & $\begin{array}{l}\text { To reduce mortality from } 10 \% \text { to } 5 \% \text {, a total sample of } \\
\text { size of } 686 \text { in the intervention group is needed (24). }\end{array}$ \\
\hline Study populations & $\begin{array}{l}\text { Severe or critical COVID-19 in hospitalized patients is } \\
\text { most commonly reported. }\end{array}$ \\
\hline \multirow[t]{3}{*}{ Outcome measurement } & $\begin{array}{l}\text { Mortality at day } 28 \text { is most commonly reported. } \\
\text { WHO response criteria recommended but not com- } \\
\text { monly reported. }\end{array}$ \\
\hline & $\begin{array}{l}\text { Secondary: IL6 levels, functional status, hospitaliza- } \\
\text { tion, ICU admission, pulmonary function at } 1,6,12 \\
\text { months. }\end{array}$ \\
\hline & $\begin{array}{l}\text { Safety and adverse event reporting in accordance } \\
\text { with best practices. }\end{array}$ \\
\hline \multirow[t]{2}{*}{ Product characterization } & $\begin{array}{l}\text { MSCs produced and characterized according to GMP } \\
\text { practices and ISCT criteria. }\end{array}$ \\
\hline & $\begin{array}{l}\text { MSC-EVs characterized in accordance with MISEV } \\
\text { criteria. }\end{array}$ \\
\hline Risk of Bias & $\begin{array}{l}\text { Studies with high risk of potential bias should not be } \\
\text { included in meta-analysis. }\end{array}$ \\
\hline
\end{tabular}

modest-sized studies, we expect meta-analysis will remain critical for a timely understanding of the potential benefit of MSCs to treat COVID-19.

\section{Declarations}

Ethics approval and consent to participate

Not applicable.

Consent for publication

Not applicable.

\section{Availability of data and materials}

Not applicable at this stage. Datasets available upon request from the corresponding author.

\section{Funding}

Support was received from internal grants from the Faculty of Medicine at the University of Ottawa (no specific grant number) and from Canadian Blood Services (Blood Efficiency Accelerator Program, 2020; no specific grant number) funded by Health Canada and provincial and territorial ministries of health in Canada.

\section{Authors' contributions}

AMK and DSA conceived the study design. AMK and MM performed study selection, data extraction and data analysis. AMK and DSA were responsible for the initial drafting of the manuscript. DSA, MML and DAF, provided important revisions for the protocol development as well as data extraction questions and reviewed data analysis and synthesis. All authors were involved in manuscript revisions before final approval.

\section{Competing interests}

DA is a paid medical consultant with Canadian Blood Services. The authors have no other competing interests to declare.

\section{Acknowledgements}

None.

\section{Supplementary materials}

Supplementary material associated with this article can be found in the online version at doi:10.1016/j.jcyt.2021.12.001.

\section{References}

[1] Ciotti M, Ciccozzi M, Terrinoni A, Jiang WC, Wang CB, Bernardini S. The COVID-19 pandemic. Crit Rev Clin Lab Sci 2020;57(6):365-88. https://doi.org/10.1080/ 10408363.2020.1783198.

[2] Hirano T, Murakami M. COVID-19: A New Virus, but a Familiar Receptor and Cytokine Release Syndrome. Immunity 2020 May 19;52(5):731-3. https://doi.org/ 10.1016/j.immuni.2020.04.003.

[3] Hojyo S, Uchida M, Tanaka K, Hasebe R, Tanaka Y, Murakami M, Hirano T. How COVID-19 induces cytokine storm with high mortality. Inflamm Regen 2020 Oct 1;40:37. https://doi.org/10.1186/s41232-020-00146-3. 
[4] Darif D, Hammi I, Kihel A, El Idrissi Saik I, Guessous F, Akarid K. The pro-inflammatory cytokines in COVID-19 pathogenesis: What goes wrong? Microb Pathog 2021;153:104799. https://doi.org/10.1016/j.micpath.2021.104799.

[5] Hu B, Huang S, Yin L. The cytokine storm and COVID-19. J Med Virol 2021;93 (1):250-6. https://doi.org/10.1002/jmv.26232.

[6] Li S, Zhang Y, Guan Z, Li H, Ye M, Chen X, Shen J, Zhou Y, Shi ZL, Zhou P, Peng K. SARS-CoV-2 triggers inflammatory responses and cell death through caspase-8 activation. Signal Transduct Target Ther 2020;5(1):235. https://doi.org/10.1038/ s41392-020-00334-0.

[7] Yap JKY, Moriyama M, Iwasaki A. Inflammasomes and Pyroptosis as Therapeutic Targets for COVID-19. J Immunol 2020;205(2):307-12. https://doi.org/10.4049/ jimmunol.2000513.

[8] Li L, Huang Q, Wang DC, Ingbar DH, Wang X. Acute lung injury in patients with COVID-19 infection. Clin Transl Med 2020;10(1):20-7. https://doi.org/10.1002/ ctm2.16.

[9] Gibson PG, Qin L, Puah SH. COVID-19 acute respiratory distress syndrome (ARDS): clinical features and differences from typical pre-COVID-19 ARDS. Med J Aust 2020;213(2). https://doi.org/10.5694/mja2.50674.54-56.e1.

[10] Majumder J, Minko T. Recent Developments on Therapeutic and Diagnostic Approaches for COVID-19. AAPS J 2021;23(1):14. https://doi.org/10.1208/ s12248-020-00532-2.

[11] Kassem DH, Kamal MM. Mesenchymal Stem Cells and Their Extracellular Vesicles: A Potential Game Changer for the COVID-19 Crisis. Front Cell Dev Biol 2020;8:587866. https://doi.org/10.3389/fcell.2020.587866.

[12] Horwitz EM, Andreef M, Frassoni F. Mesenchymal Stromal Cells. Curr Opin Hematol 2006;13(6):419-25. https://doi.org/10.1097/01.moh.0000245697.54887.6f.

[13] Le Blanc K, Frassoni F, Ball L, Locatelli F, Roelofs H, Lewis I, Lanino E, Sundberg B, Bernardo ME, Remberger M, Dini G, Egeler RM, Bacigalupo A, Fibbe W, O; Ringdén. Developmental Committee of the European Group for Blood and Marrow Transplantation. Mesenchymal stem cells for treatment of steroid-resistant, severe, acute graft-versus-host disease: a phase II study. Lancet 2008;371 (9624):1579-86. https://doi.org/10.1016/S0140-6736(08)60690-X.

[14] Forbes GM, Sturm MJ, Leong RW, Sparrow MP, Segarajasingam D, Cummins AG, Phillips M, Herrmann RP. A phase 2 study of allogeneic mesenchymal stromal cells for luminal Crohn's disease refractory to biologic therapy. Clin Gastroenterol Hepatol 2014;12(1):64-71. https://doi.org/10.1016/j.cgh.2013.06.021.

[15] Németh K, Leelahavanichkul A, Yuen PS, Mayer B, Parmelee A, Doi K, Robey PG, Leelahavanichkul K, Koller BH, Brown JM, Hu X, Jelinek I, Star RA, Mezey E. Bone marrow stromal cells attenuate sepsis via prostaglandin $\mathrm{E}(2)$-dependent reprogramming of host macrophages to increase their interleukin-10 production. Nat Med 2009;15(1):42-9. https://doi.org/10.1038/nm.1905.

[16] Huang S, Lu G, Wu Y, Jirigala E, Xu Y, Ma K, Fu X. Mesenchymal stem cells delivered in a microsphere-based engineered skin contribute to cutaneous wound healing and sweat gland repair. J Dermatol Sci 2012;66(1):29-36. https://doi.org/ 10.1016/j.jdermsci.2012.02.002.

[17] Mousaei Ghasroldasht M, Matin MM, Kazemi Mehrjerdi H, Naderi-Meshkin H, Moradi A, Rajabioun M, Alipour F, Ghasemi S, Zare M, Mirahmadi M, Bidkhori HR, Bahrami AR. Application of mesenchymal stem cells to enhance non-union bone fracture healing. J Biomed Mater Res A 2019;107(2):301-11. https://doi.org/ 10.1002/jbm.a.36441.

[18] Joel MDM, Yuan J, Wang J, Yan Y, Qian H, Zhang X, Xu W, Mao F. MSC: immunoregulatory effects, roles on neutrophils and evolving clinical potentials. Am J Transl Res 2019;11(6):3890-904

[19] Lee DK, Song SU. Immunomodulatory mechanisms of mesenchymal stem cells and their therapeutic applications. Cell Immunol 2018;326:68-76. https://doi. org/10.1016/j.cellimm.2017.08.009.

[20] Wang M, Yuan Q Xie L. Mesenchymal Stem Cell-Based Immunomodulation: Properties and Clinical Application. Stem Cells Int 2018;2018:3057624. https:// doi.org/10.1155/2018/3057624.

[21] Farouk S, Sabet S, Abu Zahra FA, El-Ghor AA. Bone marrow derived-mesenchymal stem cells downregulate IL17A dependent IL6/STAT3 signaling pathway in CCl4induced rat liver fibrosis. PLoS One 2018;13(10):e0206130. https://doi.org/ 10.1371/journal.pone.0206130.

[22] Yamawaki-Ogata A, Oshima H, Usui A, Narita Y. Bone marrow-derived mesenchymal stromal cells regress aortic aneurysm via the NF-kB, Smad3 and Akt signaling pathways. Cytotherapy 2017;19(10):1167-75. https://doi.org/10.1016/j. jcyt.2017.07.010.

[23] Gu LH, Zhang TT, Li Y, Yan HJ, Qi H, Li FR. Immunogenicity of allogeneic mesenchymal stem cells transplanted via different routes in diabetic rats. Cell Mol Immunol 2015;12(4):444-55. https://doi.org/10.1038/cmi.2014.70.

[24] Deuse T, Stubbendorff M, Tang-Quan K, Phillips N, Kay MA, Eiermann T, Phan TT, Volk HD, Reichenspurner H, Robbins RC, Schrepfer S. Immunogenicity and immunomodulatory properties of umbilical cord lining mesenchymal stem cells. Cell Transplant 2011;20(5):655-67. https://doi.org/10.3727/096368910X536473.

[25] Lalu MM, Mazzarello S, Zlepnig J, Dong YYR, Montroy J, McIntyre L, Devereaux PJ, Stewart DJ, David Mazer C, Barron CC, McIsaac DI, Fergusson DA. Safety and Efficacy of Adult Stem Cell Therapy for Acute Myocardial Infarction and Ischemic Heart Failure (SafeCell Heart): A Systematic Review and Meta-Analysis. Stem Cells Transl Med 2018;7(12):857-66. https://doi.org/10.1002/sctm.18-0120.

[26] Thompson M, Mei SHJ, Wolfe D, Champagne J, Fergusson D, Stewart DJ, Sullivan KJ, Doxtator E, Lalu M, English SW, Granton J, Hutton B, Marshall J, Maybee A, Walley KR, Santos CD, Winston B, McIntyre L. Cell therapy with intravascular administration of mesenchymal stromal cells continues to appear safe: An updated systematic review and meta-analysis. EClinicalMedicine 2020;19:100249. https://doi.org/10.1016/j.eclinm.2019.100249.
[27] Elliott JH, Synnot A, Turner T, Simmonds M, Akl EA, McDonald S, Salanti G, Meerpohl J, MacLehose H, Hilton J, Tovey D, Shemilt I, Thomas J. Living Systematic Review Network. Living systematic review: 1. Introduction-the why, what, when, and how. J Clin Epidemiol 2017;91:23-30. https://doi.org/10.1016/j.jclinepi.2017.08.010.

[28] Juul S, Nielsen EE, Feinberg J, Siddiqui F, Jørgensen CK, Barot E, Nielsen N, Bentzer $\mathrm{P}$, Veroniki AA, Thabane L, Bu F, Klingenberg S, Gluud C, Jakobsen JC. Interventions for treatment of COVID-19: A living systematic review with meta-analyses and trial sequential analyses (The LIVING Project). PLoS Med 2020;17(9):e1003293. https://doi.org/10.1371/journal.pmed.1003293.

[29] Siemieniuk RA, Bartoszko JJ, Ge L, Zeraatkar D, Izcovich A, Kum E, Pardo-Hernandez H, Qasim A, Martinez JPD, Rochwerg B, Lamontagne F, Han MA, Liu Q Agarwal A, Agoritsas T, Chu DK, Couban R, Cusano E, Darzi A, Devji T, Fang B, Fang C, Flottorp SA, Foroutan F, Ghadimi M, Heels-Ansdell D, Honarmand K, Hou L, Hou X Ibrahim Q, Khamis A, Lam B, Loeb M, Marcucci M, McLeod SL, Motaghi S, Murthy S, Mustafa RA, Neary JD, Rada G, Riaz IB, Sadeghirad B, Sekercioglu N, Sheng L, Sreekanta A, Switzer C, Tendal B, Thabane L, Tomlinson G, Turner T, Vandvik PO, Vernooij RW, Viteri-García A, Wang Y, Yao L, Ye Z, Guyatt GH, BrignardelloPetersen R. Drug treatments for covid-19: living systematic review and network meta-analysis. BMJ 2020;370:m2980. https://doi.org/10.1136/bmj.m2980.

[30] Ghosn L, Chaimani A, Evrenoglou T, Davidson M, Graña C, Schmucker C, Bollig C, Henschke N, Sguassero Y, Nejstgaard CH, Menon S, Nguyen TV, Ferrand G, Kapp P, Riveros C, Ávila C, Devane D, Meerpohl JJ, Rada G, Hróbjartsson A, Grasselli G, Tovey D, Ravaud P, Boutron I. Interleukin-6 blocking agents for treating COVID19: a living systematic review. Cochrane Database Syst Rev 2021;3:CD013881. https://doi.org/10.1002/14651858.CD013881.

[31] Liao G, Zheng K, Lalu MM, Fergusson DA, Allan DS. A Scoping Review of Registered Clinical Trials of Cellular Therapy for COVID-19 and a Framework for Accelerated Synthesis of Trial Evidence-FAST Evidence. Transfus Med Rev 2020;34(3):165-71. https://doi.org/10.1016/j.tmrv.2020.06.001.

[32] Page MJ, McKenzie JE, Bossuyt PM, Boutron I, Hoffmann TC, Mulrow CD, Shamseer L, Tetzlaff JM, Akl EA, Brennan SE, Chou R, Glanville J, Grimshaw JM, Hróbjartsson A, Lalu MM, Li T, Loder EW, Mayo-Wilson E, McDonald S, McGuinness LA, Stewart LA, Thomas J, Tricco AC, Welch VA, Whiting P, Moher D. The PRISMA 2020 statement: an updated guideline for reporting systematic reviews. Syst Rev 2021;10 (1):89. https://doi.org/10.1186/s13643-021-01626-4

[33] Kirkham AM, Monaghan M, Bailey AJM, Shorr R, Lalu MM, Fergusson DA, Allan DS Mesenchymal stromal cells as a therapeutic intervention for COVID-19: a living systematic review and meta-analysis protocol. Syst Rev 2021;10(1):249. https:// doi.org/10.1186/s13643-021-01803-5. Sep 15.

[34] McGowan J, Sampson M, Salzwedel DM, Cogo E, Foerster V, Lefebvre C. PRESS Peer Review of Electronic Search Strategies: 2015 Guideline Statement. J Clin Epidemiol 2016;75:40-6. https://doi.org/10.1016/j.jclinepi.2016.01.021.

[35] Viswanathan S, Shi Y, Galipeau J, Krampera M, Leblanc K, Martin I, Nolta J, Phinney DG, Sensebe L. Mesenchymal stem versus stromal cells: International Society for Cell \& Gene Therapy (ISCT ${ }^{\circledR}$ ) Mesenchymal Stromal Cell committee position statement on nomenclature. Cytotherapy 2019;21(10):1019-24. https://doi.org/ 10.1016/j.jcyt.2019.08.002.

[36] Théry C, Witwer KW, Aikawa E, Alcaraz MJ, Anderson JD, Andriantsitohaina R, et al. Minimal information for studies of extracellular vesicles 2018 (MISEV2018): a position statement of the International Society for Extracellular Vesicles and update of the MISEV2014 guidelines. J Extracell Vesicles 2018;7(1):1535750. https://doi.org/10.1080/20013078.2018.

[37] Sterne JAC, Savović J, Page MJ, Elbers RG, Blencowe NS, Boutron I, et al. RoB 2: a revised tool for assessing risk of bias in randomised trials. BMJ 2019;366:14898. https://doi.org/10.1136/bmj.14898.

[38] Sterne JA, Hernán MA, Reeves BC, Savović J, Berkman ND, Viswanathan M, et al ROBINS-I: a tool for assessing risk of bias in non-randomised studies of interventions. BMJ 2016;355:i4919. https://doi.org/10.1136/bmj.i4919.

[39] Murad MH, Sultan S, Haffar S, Bazerbachi F. Methodological quality and synthesis of case series and case reports. BMJ Evid Based Med 2018;23(2):60-3. https://doi. org/10.1136/bmjebm-2017-110853.

[40] Leng Z, Zhu R, Hou W, Feng Y, Yang Y, Han Q et al. Transplantation of ACE2- Mesenchymal Stem Cells Improves the Outcome of Patients with COVID-19 Pneumonia. Aging Dis 2020;11(2):216-28. https://doi.org/10.14336/AD.2020.0228.

[41] Shu L, Niu C, Li R, Huang T, Wang Y, Huang M, et al. Treatment of severe COVID-19 with human umbilical cord mesenchymal stem cells. Stem Cell Res Ther 2020;11 (1):361. https://doi.org/10.1186/s13287-020-01875-5.

[42] Meng F, Xu R, Wang S, Xu Z, Zhang C, Li Y, et al. Human umbilical cord-derived mesenchymal stem cell therapy in patients with COVID-19: a phase 1 clinica trial. Signal Transduct Target Ther 2020;5(1):172. https://doi.org/10.1038/ s41392-020-00286-5.

[43] Lanzoni G, Linetsky E, Correa D, Messinger Cayetano S, Alvarez RA, et al. Umbilical cord mesenchymal stem cells for COVID-19 acute respiratory distress syndrome: A double-blind, phase 1/2a, randomized controlled trial. Stem Cells Transl Med 2021;10(5):660-73. https://doi.org/10.1002/sctm.20-0472.

[44] Sengupta V, Sengupta S, Lazo A, Woods P, Nolan A, Bremer N. Exosomes Derived from Bone Marrow Mesenchymal Stem Cells as Treatment for Severe COVID-19. Stem Cells Dev 2020;29(12):747-54. https://doi.org/10.1089/scd.2020.0080.

[45] Feng Y, Huang J, Wu J, Xu Y, Chen B, Jiang L, Xiang H, Peng Z, Wang X. Safety and feasibility of umbilical cord mesenchymal stem cells in patients with COVID-19 pneumonia: A pilot study. Cell Prolif 2020;53(12):e12947. https://doi.org/10.1111/cpr.12947.

[46] Guo Z, Chen Y, Luo X, He X, Zhang Y, Wang J. Administration of umbilical cord mesenchymal stem cells in patients with severe COVID-19 pneumonia. Crit Care 2020;24(1):420. https://doi.org/10.1186/s13054-020-03142-8. 
[47] Sánchez-Guijo F, García-Arranz M, López-Parra M, Monedero P, Mata-Martínez C, Santos A, et al. Adipose-derived mesenchymal stromal cells for the treatment of patients with severe SARS-CoV-2 pneumonia requiring mechanical ventilation. A proof of concept study. EClinicalMedicine 2020;25:100454. https://doi.org/ 10.1016/j.eclinm.2020.100454.

[48] Hashemian SR, Aliannejad R, Zarrabi M, Soleimani M, Vosough M, Hosseini SE et al. Mesenchymal stem cells derived from perinatal tissues for treatment of critically ill COVID-19-induced ARDS patients: a case series. Stem Cell Res Ther 2021;12(1):91. https://doi.org/10.1186/s13287-021-02165-4.

[49] Qu W, Wang Z, Hare JM, Bu G, Mallea JM, Pascual JM, Caplan AI, Kurtzberg J, Zubair AC, Kubrova E, Engelberg-Cook E, Nayfeh T, Shah VP, Hill JC, Wolf ME, Prokop LJ, Murad MH, Sanfilippo FP. Cell-based therapy to reduce mortality from COVID-19: Systematic review and meta-analysis of human studies on acute respiratory distress syndrome. Stem Cells Transl Med 2020;9(9):1007-22. https://doi. org/10.1002/sctm.20-0146.

[50] Ulhaq ZS, Soraya GV. Interleukin-6 as a potential biomarker of COVID-19 progression. Med Mal Infect 2020;50(4):382-3. https://doi.org/10.1016/j.medmal.2020.04.002.

[51] Stone JH, Frigault MJ, Serling-Boyd NJ, Fernandes AD, Harvey L, Foulkes AS, et al. BACC Bay Tocilizumab Trial Investigators. Efficacy of Tocilizumab in Patients Hospitalized with Covid-19. N Engl J Med 2020;383(24):2333-44. https://doi.org 10.1056/NEJMoa2028836.

[52] Hermine O, Mariette X, Tharaux PL, Resche-Rigon M, Porcher R, Ravaud P. CORIMUNO-19 Collaborative Group. Effect of Tocilizumab vs Usual Care in Adults Hospitalized With COVID-19 and Moderate or Severe Pneumonia: A Randomized Clinical Trial. JAMA Intern Med 2021;181(1):32-40. https://doi.org/10.1001/ jamainternmed.2020.6820.

[53] Salvarani C, Dolci G, Massari M, Merlo DF, Cavuto S, Savoldi L. RCT-TCZ-COVID-19 Study Group. Effect of Tocilizumab vs Standard Care on Clinical Worsening in Patients Hospitalized With COVID-19 Pneumonia: A Randomized Clinical Trial. JAMA Intern Med 2021;181(1):24-31. https://doi.org/10.1001/jamainternmed.2020.6615. Jan 1.

[54] Liu T, Zhang J, Yang Y, Ma H, Li Z, Zhang J, Cheng J, Zhang X, Zhao Y, Xia Z, Zhang L, Wu G, Yi J. The role of interleukin-6 in monitoring severe case of coronavirus disease 2019. EMBO Mol Med 2020;12(7):e12421. https://doi.org/10.15252/ emmm.202012421.

[55] Wang L, Li Y, Xu M, Deng Z, Zhao Y, Yang M, Liu Y, Yuan R, Sun Y, Zhang H, Wang H, Qian Z, Kang H. Regulation of Inflammatory Cytokine Storms by Mesenchymal Stem Cells. Front Immunol 2021;12:726909. https://doi.org/10.3389/ fimmu.2021.726909.

[56] Sadeghi S, Soudi S, Shafiee A, Hashemi SM. Mesenchymal stem cell therapies for COVID-19: Current status and mechanism of action. Life Sci 2020:262:118493. https://doi.org/10.1016/j.lfs.2020.118493.

[57] Gupta A, Kashte S, Gupta M, Rodriguez HC, Gautam SS, Kadam S. Mesenchyma stem cells and exosome therapy for COVID-19: current status and future perspective. Hum Cell 2020;33(4):907-18. https://doi.org/10.1007/s13577-020-00407W.

58] Shi Y, Wang Y, Li Q Liu K, Hou J, Shao C, Wang Y Immunoregulatory mechanism of mesenchymal stem and stromal cells in inflammatory diseases. Nat Rev Nephrol 2018;14(8):493-507. https://doi.org/10.1038/s41581-018-0023-5.

[59] Cheng RJ, Xiong AJ, Li YH, Pan SY, Zhang QP, Zhao Y, Liu Y, Marion TN. Mesenchymal Stem Cells: Allogeneic MSC May Be Immunosuppressive but Autologous MSC Are Dysfunctional in Lupus Patients. Front Cell Dev Biol 2019;7:285. https://doi. org/10.3389/fcell.2019.00285.

[60] Domenis R, Cifù A, Quaglia S, Pistis C, Moretti M, Vicario A, Parodi PC, Fabris M Niazi KR, Soon-Shiong P, Curcio F. Pro inflammatory stimuli enhance the immunosuppressive functions of adipose mesenchymal stem cells-derived exosomes. Sci Rep 2018;8(1):13325. https://doi.org/10.1038/s41598-018-31707-9.
[61] Huang Q Wu X, Zheng X, Luo S, Xu S, Weng J. Targeting inflammation and cytokine storm in COVID-19. Pharmacol Res 2020;159:105051. https://doi.org/ 10.1016/j.phrs.2020.105051.

[62] Yin K, Wang S, Zhao RC. Exosomes from mesenchymal stem/stromal cells: a new therapeutic paradigm. Biomark Res 2019;7:8. https://doi.org/10.1186/s40364019-0159-x.

[63] Allan D, Tieu A, Lalu M, Burger D. Mesenchymal stromal cell-derived extracellular vesicles for regenerative therapy and immune modulation: Progress and challenges toward clinical application. Stem Cells Transl Med 2020;9(1):39-46. https://doi.org/10.1002/sctm.19-0114.

[64] Yan YY, Zhou WM, Wang YQ Guo QR, Zhao FX, Zhu ZY, Xing YX, Zhang HY, Aljofan M, Jarrahi AM, Makabel B, Zhang JY. The Potential Role of Extracellular Vesicles in COVID-19 Treatment: Opportunity and Challenge. Front Mol Biosci 2021;8:699929. https://doi.org/10.3389/fmolb.2021.699929.

[65] Reinders ME, Dreyer GJ, Bank JR, Roelofs H, Heidt S, Roelen DL, Zandvliet ML, Huurman VA, Fibbe WE, van Kooten C, Claas FH, Rabelink TJ, de Fijter JW. Safety of allogeneic bone marrow derived mesenchymal stromal cell therapy in renal transplant recipients: the neptune study. J Transl Med 2015;13:344. https://doi. org/10.1186/s12967-015-0700-0.

[66] Zhang J, Huang X, Wang H, Liu X, Zhang T, Wang Y, Hu D. The challenges and promises of allogeneic mesenchymal stem cells for use as a cell-based therapy. Stem Cell Res Ther 2015;6:234. https://doi.org/10.1186/s13287-015-0240-9.

[67] Bernardo ME, Pagliara D, Locatelli F. Mesenchymal stromal cell therapy: a revolution in Regenerative Medicine? Bone Marrow Transplant 2012;47(2):164-71. https://doi.org/10.1038/bmt.2011.81.

[68] Stolzing A, Scutt A. Age-related impairment of mesenchymal progenitor cell function. Aging Cell 2006:5(3):213-24. https://doi.org/10.1111/j.1474-9726.2006.00213x.

[69] de Lima KA, de Oliveira GL, Yaochite JN, Pinheiro DG, de Azevedo JT, Silva Jr WA, Covas DT, Couri CE, Simões BP, Voltarelli JC, Oliveira MC, Malmegrim KC. Transcriptional profiling reveals intrinsic mRNA alterations in multipotent mesenchymal stromal cells isolated from bone marrow of newly-diagnosed type 1 diabetes patients. Stem Cell Res Ther 2016;7(1):92. https://doi.org/10.1186/s13287-016-0351-y.

[70] Choudhery MS, Badowski M, Muise A, Pierce J, Harris DT. Donor age negatively impacts adipose tissue-derived mesenchymal stem cell expansion and differentiation. J Transl Med 2014;12:8. https://doi.org/10.1186/1479-5876-12-8.

[71] Hass R, Kasper C, Böhm S, Jacobs R. Different populations and sources of human mesenchymal stem cells (MSC): A comparison of adult and neonatal tissue-derived MSC. Cell Commun Signal 2011;9:12. https://doi.org/10.1186/1478-811X-9-12.

[72] Ribeiro A, Laranjeira P, Mendes S, Velada I, Leite C, Andrade P, Santos F, Henriques A, Grãos M, Cardoso CM, Martinho A, Pais M, da Silva CL, Cabral J, Trindade H, Paiva A. Mesenchymal stem cells from umbilical cord matrix, adipose tissue and bone marrow exhibit different capability to suppress peripheral blood B, natural killer and T cells. Stem Cell Res Ther 2013;4(5):125. https://doi.org/10.1186/ scrt336.

[73] Li CY, Wu XY, Tong JB, Yang XX, Zhao JL, Zheng QF, Zhao GB, Ma ZJ. Comparative analysis of human mesenchymal stem cells from bone marrow and adipose tissue under xeno-free conditions for cell therapy. Stem Cell Res Ther 2015;6(1):55. https://doi.org/10.1186/s13287-015-0066-5.3.

[74] Hernandez JJ, Beaty DE, Fruhwirth LL, Lopes Chaves AP, Riordan NH. Dodging COVID-19 infection: low expression and localization of ACE2 and TMPRSS2 in multiple donor-derived lines of human umbilical cord-derived mesenchymal stem cells. J Transl Med 2021;19(1):149. https://doi.org/10.1186/s12967-02102813-6.

[75] Avanzini MA, Mura M, Percivalle E, Bastaroli F, Croce S, Valsecchi C, Lenta E, Nykjaer G, Cassaniti I, Bagnarino J, Baldanti F, Zecca M, Comoli P, Gnecchi M. Human mesenchymal stromal cells do not express ACE2 and TMPRSS2 and are not permissive to SARS-CoV-2 infection. Stem Cells Transl Med 2021;10(4):636-42. https://doi.org/10.1002/sctm.20-0385. 